\title{
Elevated matrix metalloproteinase-9 expression may contribute to the pathogenesis of bladder cancer
}

\author{
FAN-CHANG ZENG ${ }^{1,2}$, SONG CEN $^{2}$, ZHENG-YAN TANG $^{1}$ and XIN-LI KANG ${ }^{2}$ \\ ${ }^{1}$ Department of Urology, Xiangya Hospital, Central South University, Changsha, Hunan 410008; \\ ${ }^{2}$ Department of Urology, People's Hospital of Hainan Province, Haikou, Hainan 570311, P.R. China
}

Received February 3, 2015; Accepted December 14, 2015

DOI: $10.3892 / 01.2016 .4187$

\begin{abstract}
The present study investigated the potential association between matrix metalloproteinase-9 (MMP-9) expression and the pathogenesis of bladder cancer. The present study reviewed previous studies published in Chinese and English using predefined selection criteria, which identified high-quality studies concerning MMP-9 and bladder cancer. Statistical analyses of the data were conducted using Comprehensive Meta-Analysis software version 2.0. In total, 23 case-control studies were selected, which consisted of 1,040 bladder cancer patients and 244 healthy controls. The expression rates and protein levels of MMP-9 were significantly increased in bladder cancer patients compared with the healthy controls, which was demonstrated using immunohistochemistry (IHC) and enzyme-linked immunosorbent assay-based methods. Furthermore, the expression rate of MMP-9 in histological G1/G2 grade bladder cancer tumors was significantly decreased compared with G3 tumors. Subgroup analysis based on ethnicity demonstrated that the rate of MMP-9 protein expression between bladder cancer patients and healthy controls was significantly different in African, Asian and Caucasian patients, which was identified using IHC. The MMP-9 protein levels in bladder cancer patients and healthy controls were significantly different between Asian and Caucasian patients, but not African patients. The differences between MMP-9 expression in ethnic groups were also evident in the expression rate of MMP-9 identified in histological G1/G2 grade tumors in Asian and Caucasian patients compared with G3 grade tumors, which was not evident in
\end{abstract}

Correspondence to: Dr Zheng-Yan Tang, Department of Urology, Xiangya Hospital, Central South University, 87 Xiangya Road, Changsha, Hunan 410008, P.R. China

E-mail: tangzhengyan1111@163.com

Abbreviations: ELISA, enzyme-linked immunosorbent assay; MMP, matrix metalloproteinase; IHC, immunohistochemistry; OR, odds ratio; $\mathrm{CI}$, confidence interval

Key words: bladder cancer, matrix metalloproteinase-9, expression, association, meta-analysis, matrix metalloproteinase
African patients. In conclusion, the present meta-analysis results markedly indicate that MMP-9 expression is associated with clinicopathological features of bladder cancer, suggesting that MMP-9 may be a useful biomarker in the diagnosis and clinical management of bladder cancer, and may be a valuable therapeutic target.

\section{Introduction}

Worldwide, bladder cancer is the 7th most common cancer in men and the 17 th most common cancer in women (1). Notably, in the developed world, bladder cancer ranks as the 4th and 9th most common cancer in men and women, respectively (2). An estimated 375,000 bladder cancer cases are reported each year around the world, with 68,810 novel cases and 14,100 mortalities reported in the United States in 2013 (3). Transitional cell carcinoma is the most frequently occurring type of bladder cancer. Other bladder cancer types consist of adenocarcinoma, squamous cell carcinoma and small cell bladder cancer $(4,5)$. Notably, the incidence of bladder cancer increases with age, particularly in men (6). Bladder cancer arises as a result of multistep alterations, among which metastasis is crucial (7). Epidemiological studies have demonstrated that several environmental factors may contribute to bladder cancer risk, including smoking, chronic inflammation, radiation exposure, anticancer drugs and aromatic amines, which are contained in dyes $(6,8)$. The treatment of bladder cancer is based on multiple parameters, including the extent of the disease, bladder cancer stage and the results of a bladder cystoscopy, which evaluates the tumor (9). The currently available treatments are not effective and the mechanisms of initiation and progression of bladder cancer remain unresolved due to a lack of effective early diagnostic tools and clinical prognostic markers (10). Nevertheless, previous studies have identified a few markers that are associated with bladder cancer progression, including the tumor stage, grade, invasion, growth and metastasis (11). However, additional molecular targets that accurately predict bladder cancer progression are urgently required.

The matrix metalloproteinases (MMPs), a family of zinc-dependent endopeptidases with proteolytic activity against extracellular matrix components (12), are involved in numerous physiological processes, including tissue remodeling, embryonic development and reproduction (13). However, the overexpression of MMPs is also observed in 
several diseases (14). The levels of particular MMPs, including the interstitial collagenase MMP-1, stromelysin-1 MMP-3, gelatinases MMP-2 and MMP-9 and stromelysin-3 MMP-11, are increased in tumor tissues, and promote the invasion of malignant cells, regulate tumor growth and metastasis and are associated with a poor overall survival rate (15). MMP-9 has multiple substrates; however, collagen type IV, the main component of basement membranes, is the most crucial MMP-9 substrate in a tumor microenvironment (16). The proteolytic activity of MMP-9 against collagen type IV not only promotes invasion and metastasis, but also releases matrix-bound growth factors and other signaling molecules to promote growth signaling, angiogenesis and an inflammatory response $(9,17)$. Previous studies have revealed that MMP-9 is involved in the pathogenesis of bladder cancer $(3,9,15,18)$; however, alternative studies fail to establish an association between MMP-9 expression and bladder cancer, leading to the conclusion that MMP-9 may not be an effective marker for bladder cancer detection $(19,20)$. Due to the conflicting results of previous studies, the present study investigated the association between MMP-9 and the pathogenesis of bladder cancer using a retrospective meta-analysis.

\section{Materials and methods}

Literature search. The present study conducted a systematic literature search of studies published prior to October 2014, using PubMed (National Center for Biotechnology Information, U.S. National Library of Medicine, Bethesda, MD, USA), EBSCO Industries, Inc. (Birmingham, AL, USA), Ovid (New York, NY, USA), SpringerLink (Berlin, Germany), Wiley (London, UK), Web of Science (New York, NY, USA), Wanfang (Beijing, China), China National Knowledge Infrastructure (Beijing, China) and Chongqing VIP Information Co., Ltd (Chongqing, China) databases. The literature search was restricted to retrieving studies published in Chinese and English. The following search keywords were used: Matrix metalloproteinase; MMP; bladder cancer; urinary bladder neoplasms; neoplasms; bladder; malignant tumor of urinary bladder; cancer of bladder; bladder tumors; and urinary bladder cancer.

Study selection criteria. Published studies were selected based on the following inclusion criteria: The studies were case-control studies; the case group contained pathology-verified bladder cancer patients and the control group consisted of healthy individuals; the detection methods were enzyme-linked immunosorbent assays (ELISA) and immunohistochemistry (IHC); and the end results were defined as expression rates and protein levels of MMP-9 in bladder cancer tissues. The exclusion criteria were as follows: Studies that were letters, reviews and meta-analyses; studies that were not associated with MMP-9 and bladder cancer; non-human studies; and studies with incomplete data. When there were multiple studies written by the same author, the study with the most applicable information and largest number of cases was used.

Statistical analysis. Odds ratio (OR) at $95 \%$ confidence intervals $(\mathrm{CI})$ were calculated using the fixed or random effects model. The significance of the overall effect size was estimated by the Z-test (21). Forest plots were created to demonstrate the differences in the OR at $95 \%$ CI between groups. The heterogeneity was assessed using a Galbraith radial plot (22) and Cochran's Q-test (21); heterogeneity was regarded as $\mathrm{P}_{\mathrm{h}}<0.05$. A Galbraith radial plot is a scatter plot of standardized estimates against reciprocals of standard errors, possibly with respect to a transformed scale, designed so that the original estimates may be compared and interpreted. Heterogeneity is indicated if the dot lies beyond the $95 \%$ CI, otherwise no heterogeneity existed. In addition, $\mathrm{I}^{2}$ test was used to evaluate the degree of heterogeneity (24). If there was heterogeneity among studies $\left(\mathrm{P}_{\mathrm{h}}<0.05\right.$ or $\left.\mathrm{I}^{2}>50 \%\right)$, a random effects model was applied; otherwise a fixed effects model was used (25). Sensitivity analysis was conducted to estimate the effects of a single study on the overall results. Publication bias was evaluated by classic fail-safe N, funnel plots and Egger's test (26-28). All statistical analyses were performed using Comprehensive Meta-Analysis software version 2.0 (Biostat, Inc., Englewood, NJ, USA).

\section{Results}

Baseline characteristics. The present literature search initially retrieved 358 relevant articles, 132 of which were studies published in Chinese and 253 were studies published in English. In total, 299 of the studies were not included, as follows: Duplicates, $n=8$; letters or reviews, $n=12$; non-human studies, $n=15$; and not relevant to the present study topic, $n=264$. The full text of the remaining studies $(n=86)$ was reviewed. Additional studies were excluded as they were not case-control or cohort studies $(n=19)$, were irrelevant to the present study $(n=4)$ or possessed incomplete data $(n=1)$. Overall, 23 case-control studies (15,18-20,29-47), published between 1998 and 2014, were selected for meta-analysis, and consisted of 1,040 bladder cancer patients and 244 healthy control individuals. Among the 23 studies, the study subjects in 3 studies were African, 14 studies enrolled Asian subjects and 6 studies enrolled Caucasian subjects. All sample sources from the study subjects were tissues, and the detection methods consisted of ELISA and IHC. Baseline characteristics of the studies are presented in Table I.

Association between MMP-9 and bladder cancer. The results of the Galbraith radial plot and Cochran's Q-test demonstrated that the OR estimates for all included studies were within the $95 \% \mathrm{CI}$ of the OR from the main analysis, suggesting no heterogeneity existed in the rate of MMP-9 protein expression between bladder cancer patients and healthy control individuals (case vs. control, $\mathrm{P}_{\mathrm{h}}=0.448$ and $\mathrm{I}^{2}=0.430 \%$; histological G1/G2 vs. $\mathrm{G} 3$ grade, $\mathrm{P}_{\mathrm{h}}=0.357$ and $\mathrm{I}_{2}=8.58 \%$ ). Therefore, a fixed effects model was applied. The MMP-9 protein levels demonstrated heterogeneity between bladder cancer patients and healthy control individuals, with 4 studies beyond the $95 \% \mathrm{CI}$ $\left(\mathrm{P}_{\mathrm{h}}<0.001\right.$ and $\left.\mathrm{I}^{2}=95.212 \%\right)$. Therefore, a random effects model was used (Fig. 1). Meta-analysis results demonstrated that the expression rates of MMP-9 in bladder cancer patients were significantly increased compared with the healthy control individuals (OR, 18.589; 95\% CI, 11.630-29.711; P<0.001). MMP-9 protein levels in patients with bladder cancer were markedly higher compared with the healthy control individuals, which was at a statistically significant level [standardized mean difference 


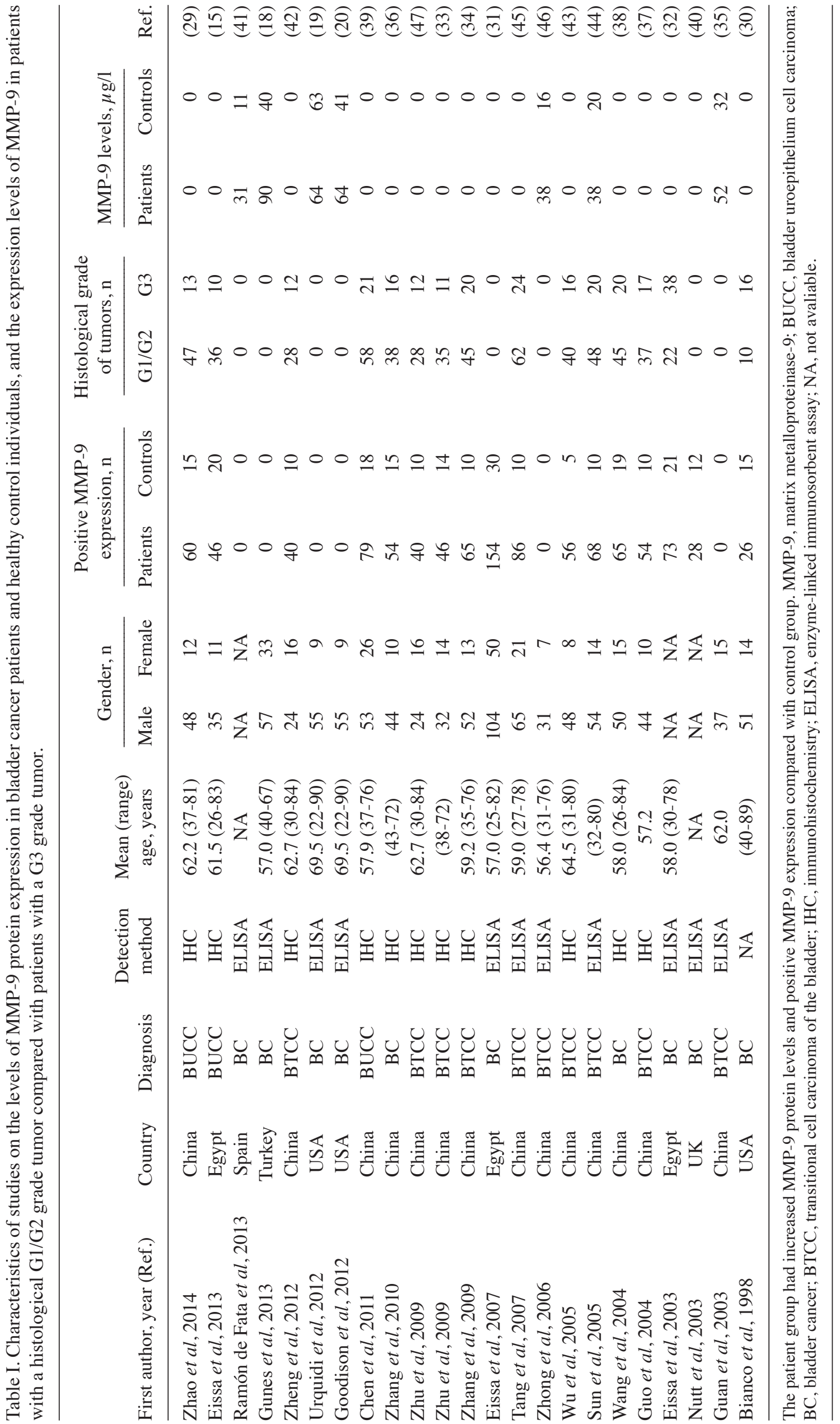


A
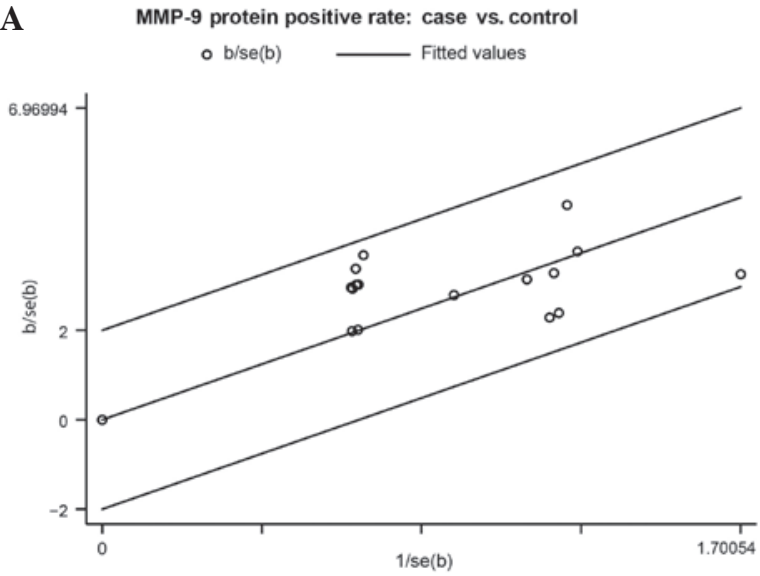

B MMP-9 protein levels $(\mu \mathrm{g} / \mathrm{l})$ : case vs. control

$\circ \mathrm{b} / \mathrm{se}(\mathrm{b}) \quad$ Fitted values

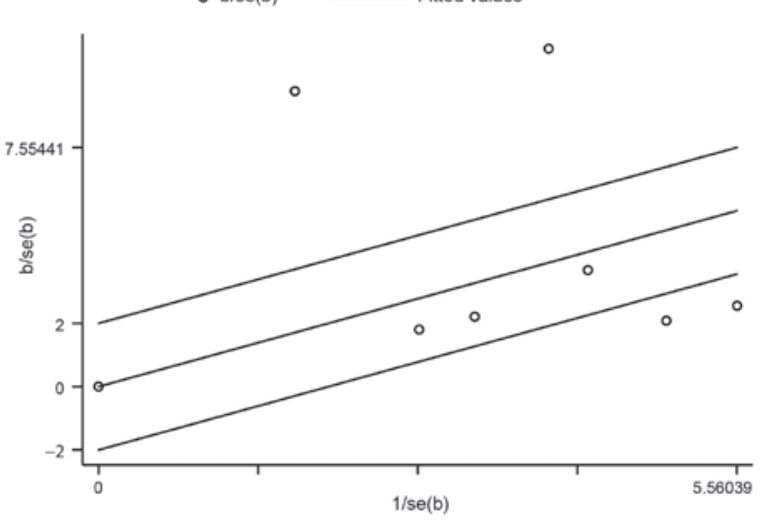

C

Histological grade: G1/G2 vs. G3

$\circ \mathrm{b} / \mathrm{se}(\mathrm{b}) \quad$ Fitted values

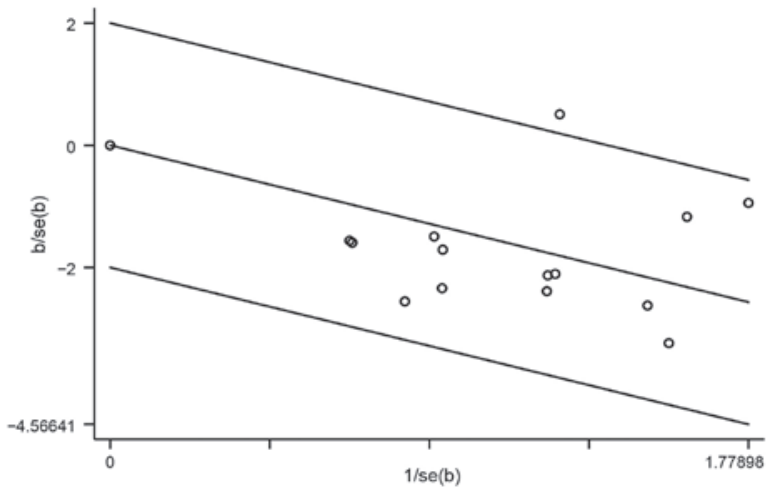

Figure 1. Galbraith radial plots for the heterogeneity of studies in terms of the association between (A) the expression rate and (B) protein levels of MMP-9 and the pathogenesis of bladder cancer, and (C) the expression rate of MMP-9 and the histological grade G1/G2 and G3 of tumors. MMP-9, matrix metalloproteinase-9.

(SMD), 1.517; 95\% CI, 0.631-2.403; P=0.001]. Furthermore, among histological grades, the expression rates of MMP-9 in tumor histological G1/G2 grade was significantly decreased compared with G3 grade (OR, 0.236; 95\% CI, 0.154-0.362; $\mathrm{P}<0.001$; Fig. 2). Subgroup analysis based on ethnicity demonstrated that the rates of MMP-9 protein expression between bladder cancer patients and healthy controls were significantly different in African (OR, 18.022; 95\% CI, 5.074-64.010; $\mathrm{P}<0.001)$, Asian (OR, 16.433; 95\% CI, 9.760-27.668; $\mathrm{P}<0.001)$ and Caucasian patients (OR, 133.553; 95\% CI, 17.352-1027.937; $\mathrm{P}<0.001)$. The MMP-9 protein levels in bladder cancer patients and healthy controls were significantly different in Asian (SMD, 2.256; 95\% CI, 0.168-4.345; $\mathrm{P}=0.034$ ) and Caucasian (SMD, 1.060; 95\% CI, 0.003-2.117; $\mathrm{P}=0.049$ ) study subjects. Furthermore, the expression rates of MMP-9 between G1/G2 and G3 tumors demonstrated significant differences in Asian (OR, 0.175; 95\% CI, 0.107-0.288; $\mathrm{P}<0.001$ ) and Caucasian patients (OR, 0.044; 95\% CI, 0.004-0.484; $\mathrm{P}=0.011$ ), while there was no clear difference in African patients (OR, 0.803; 95\% CI, 0.326-1.975; P=0.632; Fig. 3).

The results of the sensitivity analysis suggested that no study had a significant effect on the polled OR (Fig. 4). The funnel plot demonstrated no evidence of clear asymmetry, suggesting no publication bias regarding the MMP-9 protein levels in bladder cancer patients and healthy individuals. This was additionally confirmed by classic fail-safe $\mathrm{N}$ and the Egger's test $(\mathrm{P}=0.11)$. The funnel plot, classic fail-safe $\mathrm{N}$ and Egger's test demonstrated the existence of a publication bias regarding the expression rates of MMP-9 in bladder cancer patients compared with the expression rates in the healthy control individuals $(\mathrm{P}<0.05)$. Furthermore, publication bias in the selected studies, regarding the expression rates of MMP-9 in histology G1/G2 tumor grade and G3 grade, were identified $(\mathrm{P}<0.05$; Fig. 5).

\section{Discussion}

In the developed world, bladder cancer is the 4th most common malignancy among men (2). Epidemiological studies have demonstrated that several environmental factors may increase the risk of bladder cancer, including smoking, chronic inflammation, radiation exposure, anticancer drugs and aromatic amines, which are contained in dyes $(2,6)$.

The present study conducted a meta-analysis to investigate the association between MMP-9 and bladder cancer. The present results revealed that the expression rates of MMP-9 in bladder cancer patients were significantly increased compared with the expression rates in the healthy control individuals, suggesting that the MMP-9 protein is associated with the pathogenesis of bladder cancer. Furthermore, MMP-9 protein levels in patients with bladder cancer were significantly increased compared with the protein levels in the healthy control individuals, suggesting that the MMP-9 protein may be associated with a risk of bladder cancer. MMPs degrade various components of the extracellular matrix, which is important in numerous biological processes, including embryogenesis and 


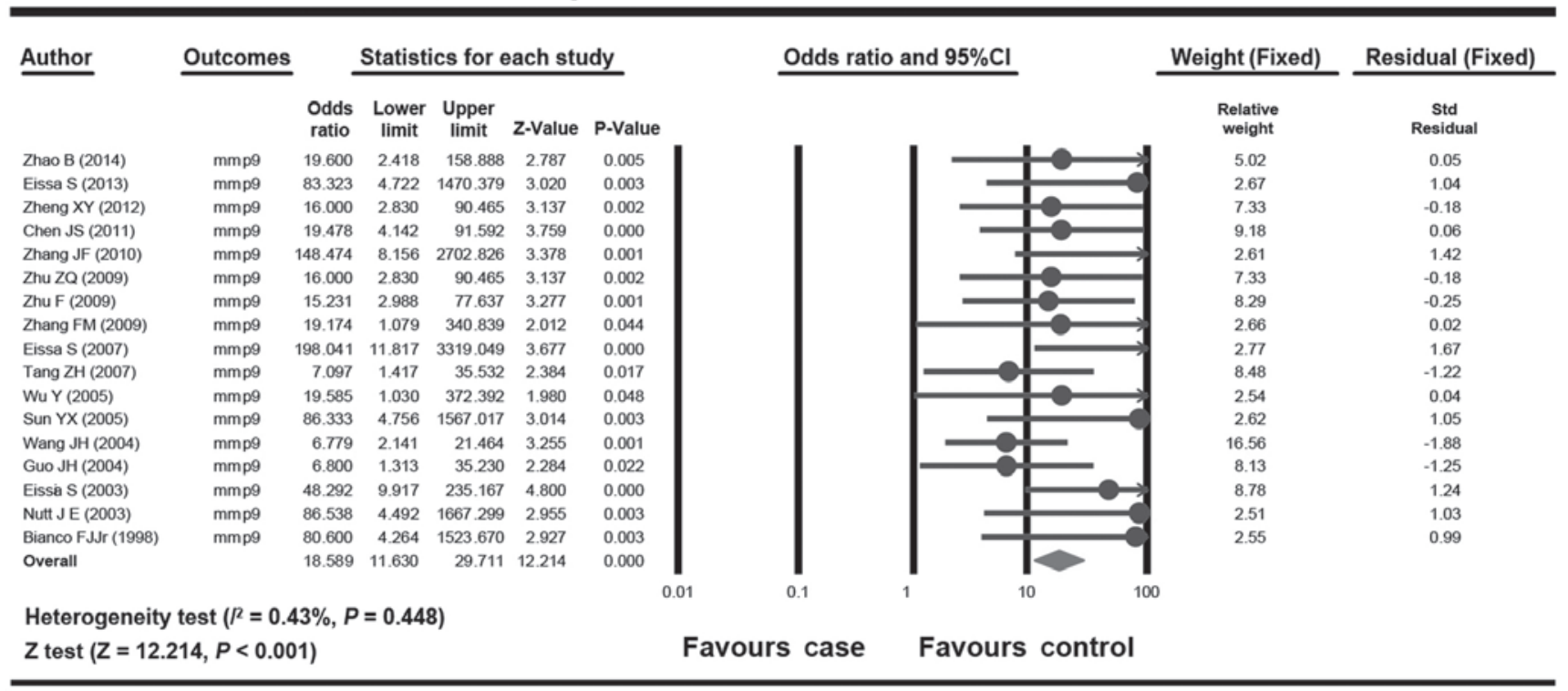

\begin{tabular}{|c|c|c|c|c|c|c|c|c|c|c|}
\hline \multirow[t]{2}{*}{ Author } & \multirow[b]{2}{*}{$\begin{array}{l}\text { Std diff } \\
\text { in means }\end{array}$} & \multicolumn{5}{|c|}{ Statistics for each study } & \multirow[b]{2}{*}{ P-Value } & \multirow[t]{2}{*}{ Std diff in means and $95 \% \mathrm{Cl}$} & \multirow{2}{*}{$\frac{\text { Weight (Random) }}{\begin{array}{c}\text { Relative } \\
\text { weight }\end{array}}$} & \multirow{2}{*}{$\begin{array}{c}\text { Residual (Random) } \\
\text { Std } \\
\text { Residual }\end{array}$} \\
\hline & & $\begin{array}{l}\text { Standard } \\
\text { error }\end{array}$ & Variance & $\begin{array}{l}\text { Lower } \\
\text { limit }\end{array}$ & $\begin{array}{l}\text { Upper } \\
\text { limit }\end{array}$ & Z-Value & & & & \\
\hline Ramon de $F$ ate $F(2013)$ & 0.646 & 0.358 & 0.128 & -0.056 & 1.348 & 1805 & 0.071 & & 14.02 & -0.78 \\
\hline Gunes M (2013) & 2722 & 0.254 & 0.065 & 2224 & 3220 & 10.709 & 0000 & & 14.66 & 1.11 \\
\hline Urquidi V (2012) & 0.460 & 0.180 & 0.032 & 0.107 & 0812 & 2557 & 0011 & & 15.00 & -0.98 \\
\hline Goodison S (2012) & 0.420 & 0.202 & 0.041 & 0.024 & 0.816 & 2079 & 0.038 & & 14.91 & -1.02 \\
\hline zhong A (2006) & 0.675 & 0.305 & 0.093 & 0.077 & 1273 & 2213 & 0.027 & & 14.36 & -0.76 \\
\hline Sun YX (2005) & 5462 & 0.578 & 0.334 & 4.330 & 6594 & 9458 & 0000 & & 1229 & 327 \\
\hline Guan KP (2003) & 0.863 & 0.234 & 0.055 & 0.404 & 1.323 & 3685 & 0.000 & & 14.76 & -0.60 \\
\hline Overall & 1.517 & 0.452 & 0.204 & 0.631 & 2403 & 3355 & 0001 & & & \\
\hline & & & & & & & 8.00 & -4.00 & 800 & \\
\hline \multicolumn{11}{|c|}{ Heterogeneity test $\left(I^{2}=95.212 \%, P<0.001\right)$} \\
\hline \multicolumn{11}{|c|}{$Z$ test $(Z=3.355, P=0.001)$} \\
\hline \multicolumn{11}{|c|}{ Random effects analysis } \\
\hline
\end{tabular}

C

Histological grade: G1/G2 vs. G3

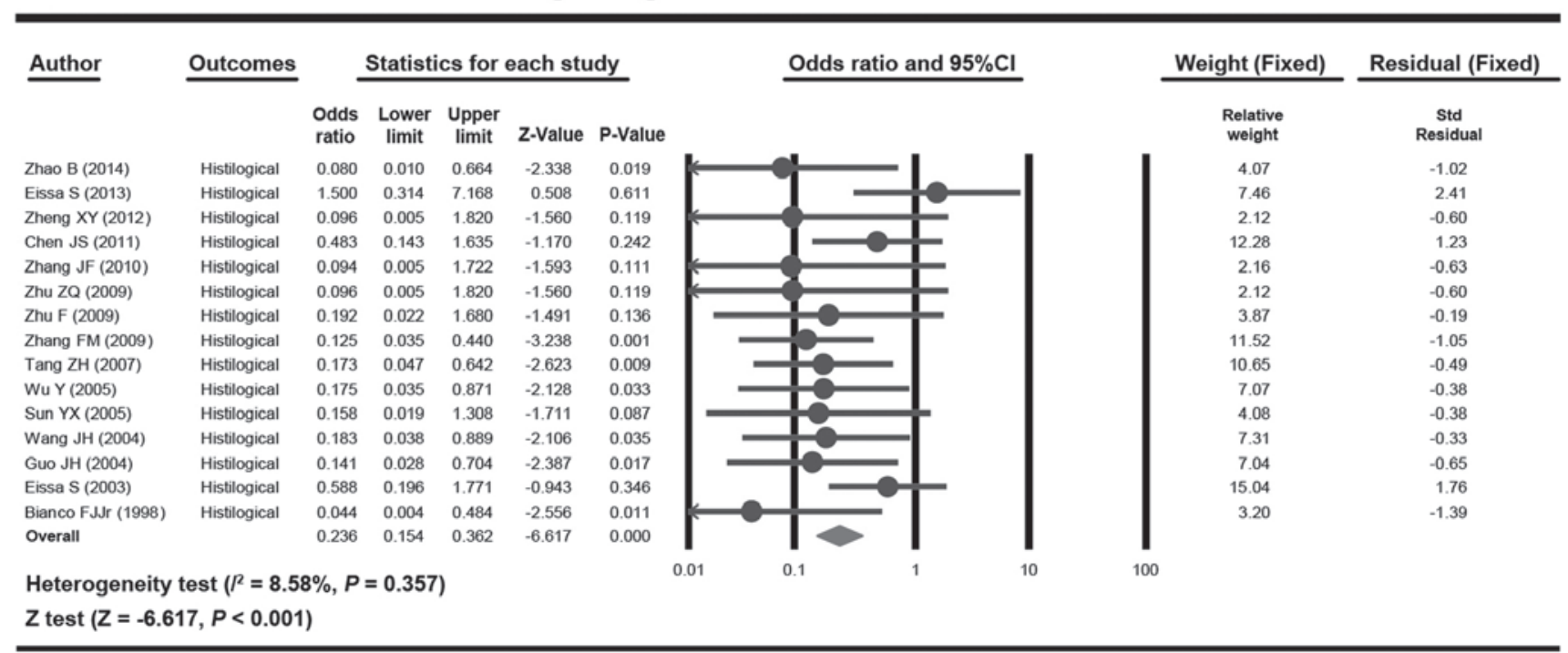

Figure 2. Forest plots of (A) the expression rate and (B) protein levels of MMP-9 in bladder cancer patients and healthy controls, and (C) the expression rate of MMP-9 between patients with histological grade G1/G2 and G3 tumors. MMP-9, matrix metalloproteinase-9; CI, confidence interval. 
A

MMP-9 protein positive rate: Ethnicity (case vs. control)

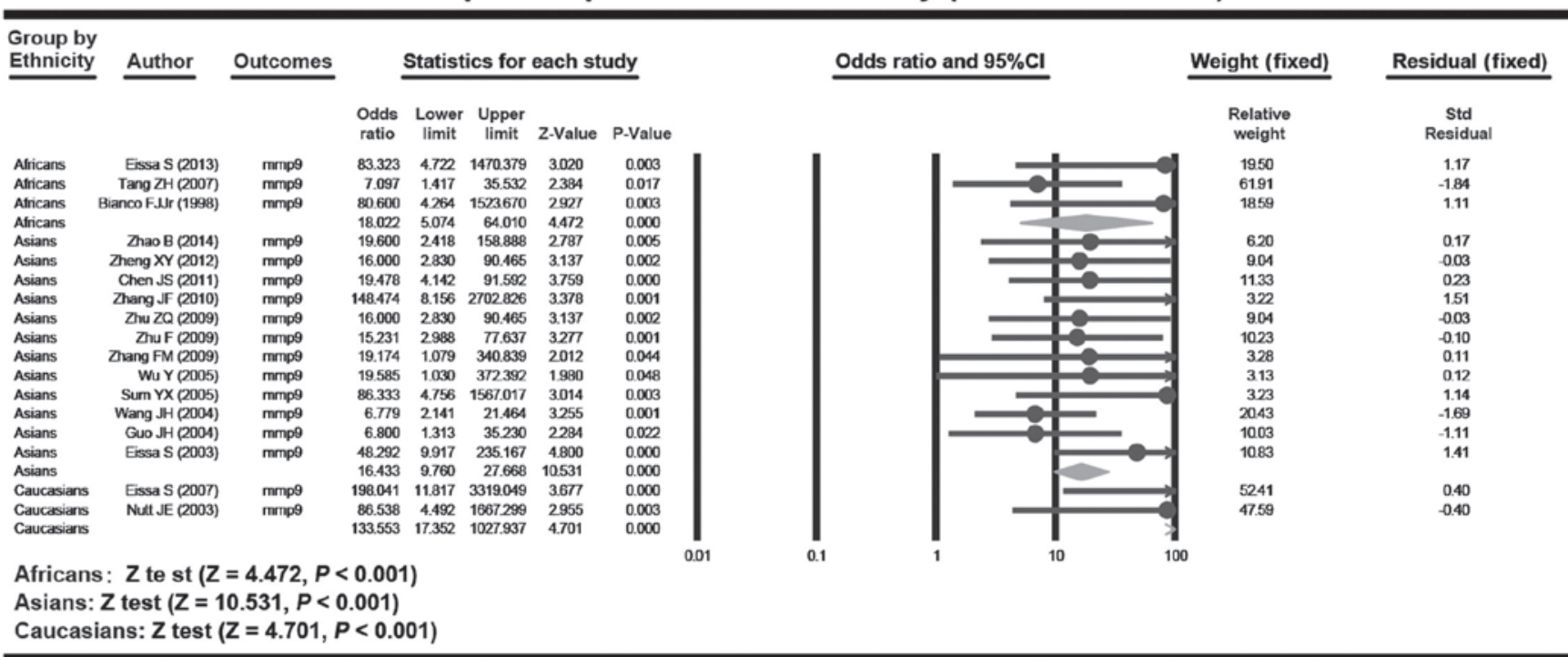

B

MMP-9 protein levels $(\mu \mathrm{g} / \mathrm{l})$ : Ethnicity (case vs. control)

\begin{tabular}{|c|c|c|c|c|c|c|c|c|c|c|c|}
\hline \multirow[t]{2}{*}{$\begin{array}{l}\text { Group by } \\
\text { Ethnicity }\end{array}$} & \multirow[t]{2}{*}{ Author } & \multicolumn{7}{|c|}{ Statistics for each study } & Std diff in means and $95 \% \mathrm{Cl}$ & Weight (random) & \multirow{2}{*}{$\frac{\text { Residual (random) }}{\begin{array}{c}\text { Std } \\
\text { Residual }\end{array}}$} \\
\hline & & $\begin{array}{l}\text { Std diff } \\
\text { in means }\end{array}$ & $\begin{array}{l}\text { Standard } \\
\text { error }\end{array}$ & Variance & $\begin{array}{l}\text { Lower } \\
\text { limit }\end{array}$ & $\begin{array}{l}\text { Upper } \\
\text { limit }\end{array}$ & z-value & p.value & & $\begin{array}{c}\text { Relative } \\
\text { weight }\end{array}$ & \\
\hline Asians & zhong A (2006) & 0675 & 0305 & 0093 & aor & 1273 & 2213 & 0027 & R & 3396 & .106 \\
\hline Asians & SunYX (2005) & 5462 & 0.578 & 0.334 & 4330 & 6594 & 2458 & 0000 & & 31.68 & 205 \\
\hline Asians & Guan KP (2003) & 0863 & 0234 & 0.055 & 0.404 & 1323 & 3685 & 0000 & & 34,35 & 095 \\
\hline Asians & & 2256 & 1.065 & 1.135 & 0168 & 4345 & 2118 & 0034 & & & \\
\hline Caucasians & Ramon de Fata F (2013) & 0646 & 0358 & 0.128 & 0056 & 1348 & 1805 & 0071 & & 23.72 & .043 \\
\hline Caucasians & Gunes M (2013) & 2722 & 0254 & 0065 & 2224 & 3220 & 10709 & 0000 & & 2501 & 178 \\
\hline Caucasians & Urquidi V (2012) & 0.460 & 0.180 & 0.032 & 0.107 & 0812 & 2557 & 0011 & & 25.73 & 065 \\
\hline Caucasiars & Goodsson S (2012) & 0420 & 0202 & 0.041 & 0024 & 0816 & 2079 & 0038 & & 25.54 & .669 \\
\hline Caucasians & & 1060 & 0.539 & 0291 & 0003 & 2117 & 1965 & 0049 & & & \\
\hline \multicolumn{9}{|c|}{ Asians: $Z$ test $(Z=2.118, P=0.034)$} & 400 & 800 & \\
\hline \multicolumn{9}{|c|}{ Caucasians: $Z$ test $(Z=1.965, P=0.049)$} & & & \\
\hline
\end{tabular}

C

Histological grade: Ethnicity (G1/G2 vs. G3)

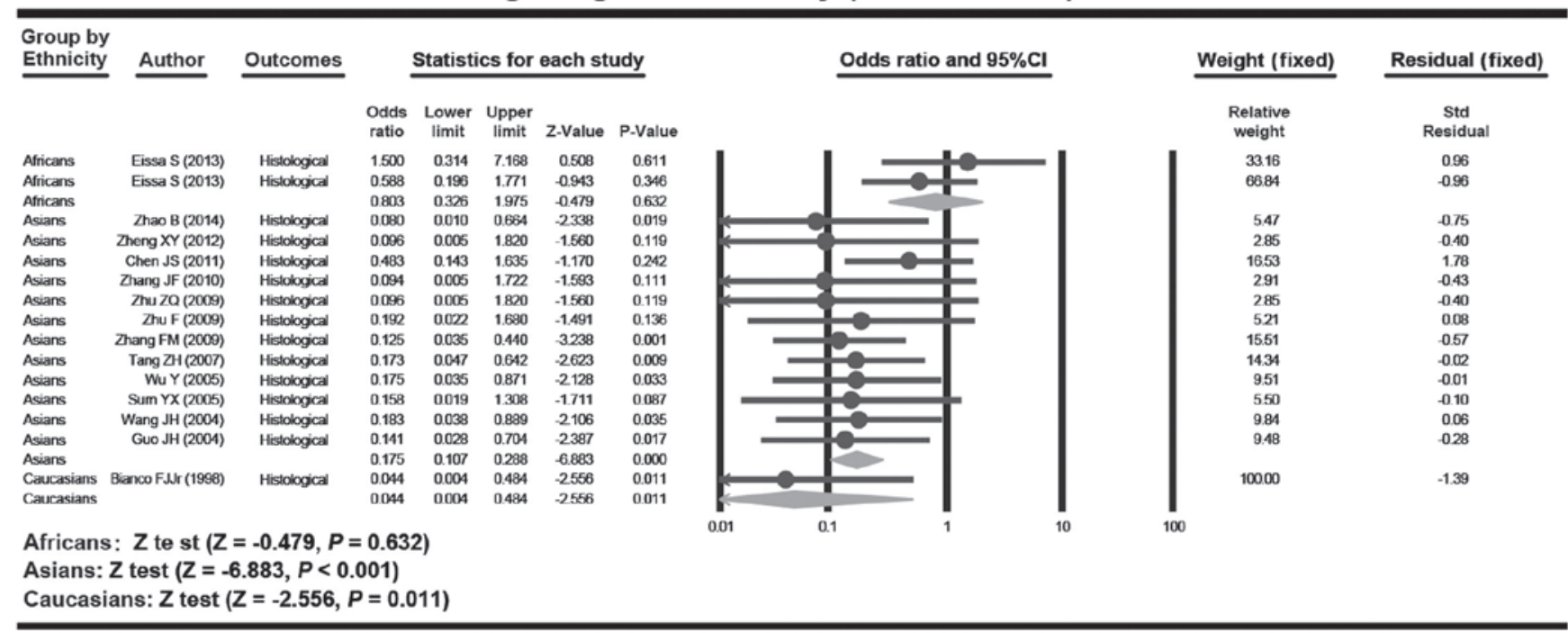

Figure 3. Forest plots of the ethnicity subgroup analyses for (A) the expression rate and (B) protein levels of MMP-9 in bladder cancer patients and healthy controls, and (C) the expression rate of MMP-9 in patients with histological grade G1/G2 and G3 tumors. MMP-9, matrix metalloproteinase-9; CI, confidence interval.

tissue repair (48). However, the degradation of the extracellular matrix has severe adverse consequences in pathological conditions; for instance, the increased expression and activity of MMP-2 have been reported in a variety of pathological cardiovascular conditions, including hypertension (49-51). Previous studies indicate that MMPs may not only be involved in promoting invasion and metastasis, but are vital in the majority of steps leading to cancer development (52-54). 
MMP-9 protein positive rate: case vs. control

\begin{tabular}{|c|c|c|c|c|c|c|c|c|c|}
\hline \multirow[t]{2}{*}{ Author } & \multirow[t]{2}{*}{ Outcomes } & \multicolumn{4}{|c|}{ Statistics with study removed } & & \multirow{2}{*}{\multicolumn{2}{|c|}{$\begin{array}{l}\text { Odds ratio }(95 \% \mathrm{Cl}) \\
\text { with study removed }\end{array}$}} & \\
\hline & & Point & $\begin{array}{c}\text { Lower } \\
\text { limit }\end{array}$ & $\begin{array}{c}\text { Upper } \\
\text { limit }\end{array}$ & Z-Value & P-Value & & & \\
\hline Zhao B (2014) & mmp9 & 18.537 & 11.456 & 29.993 & 11.892 & 0.000 & & & \\
\hline Eissa S (2013) & mmp9 & 17.840 & 11.090 & 28.697 & 11.880 & 0.000 & & & \\
\hline Zheng XY (2012) & mmp9 & 18.811 & 11.557 & 30.618 & 11.806 & 0.000 & & & \\
\hline Chen JS (2011) & mmp9 & 18.501 & 11.311 & 30.263 & 11.621 & 0.000 & & & \\
\hline Zhang JF (2010) & mmp9 & 17.581 & 10.931 & 28.277 & 11.824 & 0.000 & & & \\
\hline Zhu ZQ (2009) & mmp9 & 18.811 & 11.557 & 30.618 & 11.806 & 0.000 & & & \\
\hline Zhu F (2009) & mmp9 & 18.927 & 11.598 & 30.885 & 11.769 & 0.000 & & & \\
\hline Zhang FM (2009) & mmp9 & 18.573 & 11.547 & 29.876 & 12.047 & 0.000 & & & \\
\hline Tang ZH (2007) & mmp9 & 20.323 & 12.448 & 33.180 & 12.042 & 0.000 & & & \\
\hline Wu Y (2005) & mmp9 & 18.564 & 11.544 & 29.851 & 12.053 & 0.000 & & & \\
\hline Sun YX (2005) & mmp9 & 17.837 & 11.090 & 28.689 & 11.883 & 0.000 & & & \\
\hline Wang JH (2004) & mmp9 & 22.708 & 13.590 & 37.944 & 11.921 & 0.000 & & & \\
\hline Guo JH (2004) & mmp9 & 20.318 & 12.457 & 33.142 & 12.064 & 0.000 & & & \\
\hline Eissa S (2003) & mmp9 & 16.958 & 10.378 & 27.708 & 11.299 & 0.000 & & & \\
\hline Bianco F JJr (1998) & $\mathrm{mmp} 9$ & 17.890 & 11.125 & 28.769 & 11.900 & 0.000 & & & \\
\hline Eissa S (2007) & mmp9 & 17.378 & 10.801 & 27.961 & 11.766 & 0.000 & & & \\
\hline Nutt J E (2003) & mmp9 & 17.866 & 11.111 & 28.729 & 11.896 & 0.000 & & & \\
\hline \multirow[t]{2}{*}{ Overall } & & 18.589 & 11.630 & 29.711 & 12.214 & 0.000 & & & \\
\hline & & & & & & 0.01 & 0.1 & 10 & 100 \\
\hline
\end{tabular}

B

MMP-9 protein levels $(\mu \mathrm{g} / \mathrm{l})$ : case vs. control

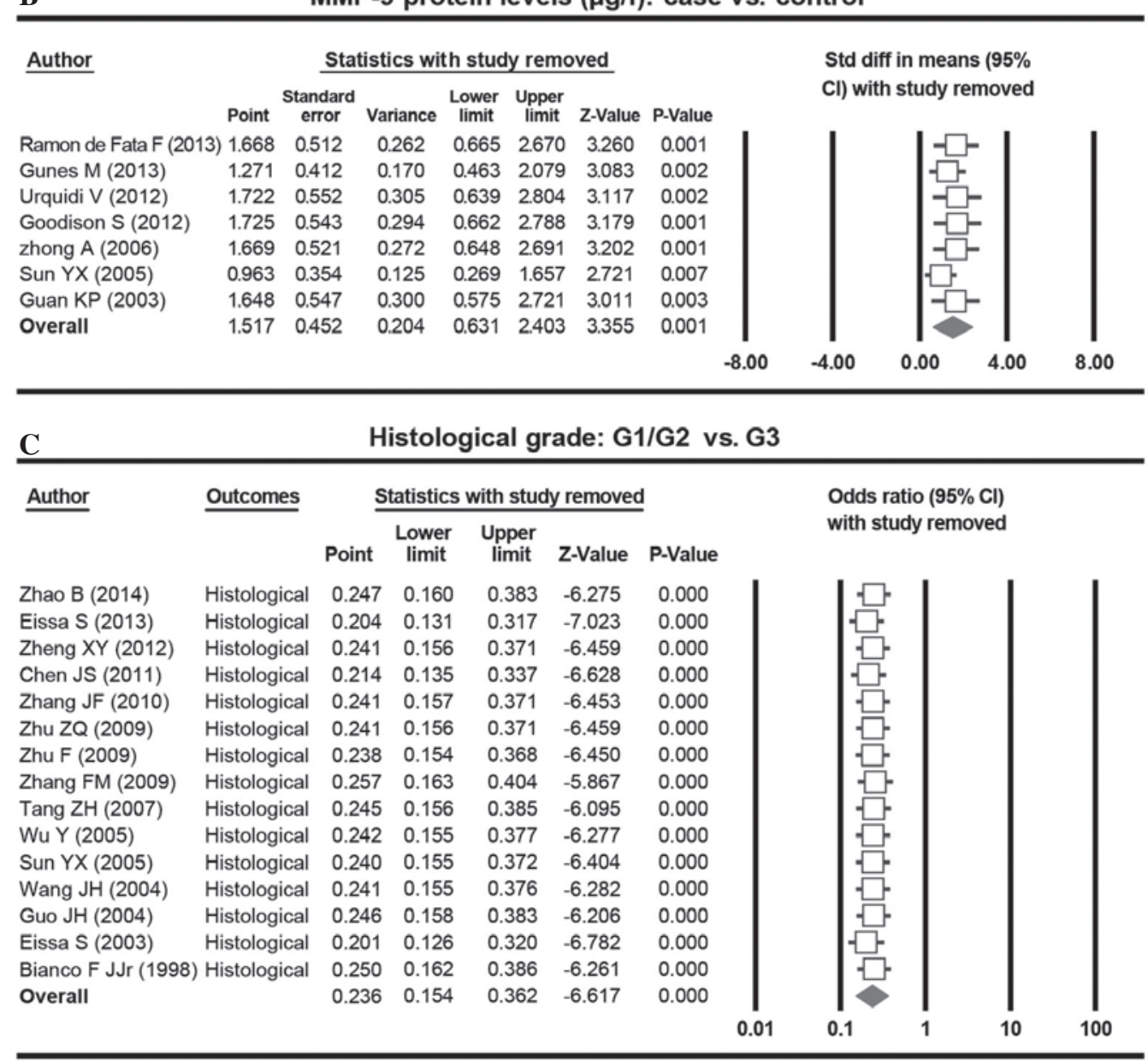

Figure 4. Sensitivity analysis of the differences in the (A) expression rate and (B) protein levels of MMP-9 in bladder cancer patients and healthy controls, and (C) the expression rate of MMP-9 in patients with histological grade G1/G2 and G3 tumors. MMP-9, matrix metalloproteinase-9; CI, confidence interval.

Tumor cells overproduce MMP-9, leading to the degradation of type IV collagen and the basement membrane, which disrupts tissue architecture and function (55). The present findings are consistent with previous studies, which suggested that MMP-9 plays a role in bladder cancer $(56,57)$. The present study identified that the expression rates of MMP-9 in bladder cancer patients was significantly increased compared with healthy control individuals $(6,9)$. 
A

MMP-9 protein positive rate: case vs. control

Funnel Plot of precision by Log odds ratio

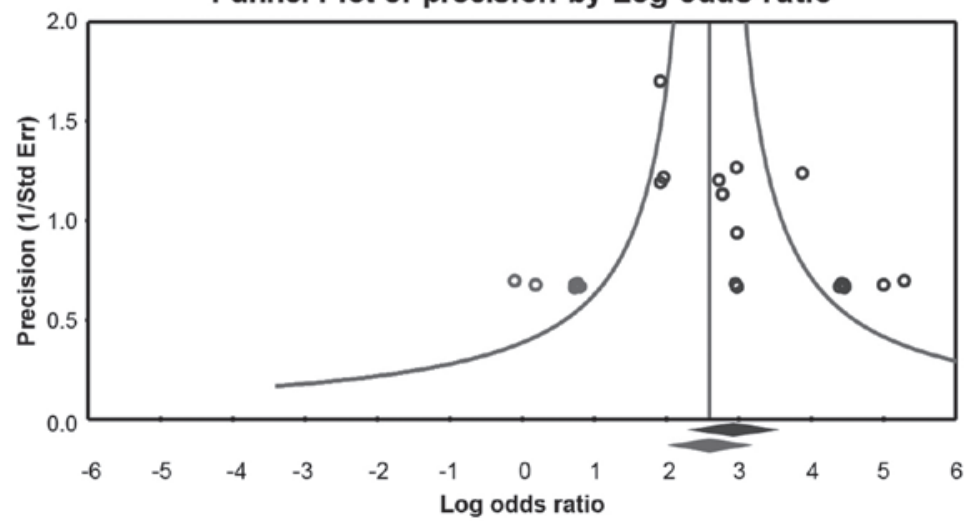

\section{Classic fail-safe $\mathbf{N}$}

Z-value for observed studies

P.vatue for observed studes

Alpha

Tails

$Z$ for apha

Number of observed studies

0.00000

1.95996
1700000

Number of missing studies that would bring p-value to > alpha 682.00000

Egger's regression intercept

Intercept

Standard error

$95 \%$ lower limit (2-tailed)

$95 \%$ upper limit (2-tailed)

t-value

of

P-value (2-tailed)

Log odds ratio

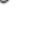

B

MMP-9 protein levels ( $\mu \mathrm{g} / \mathrm{l})$ : case vs. control

Funnel Plot of precision by Std diff in means

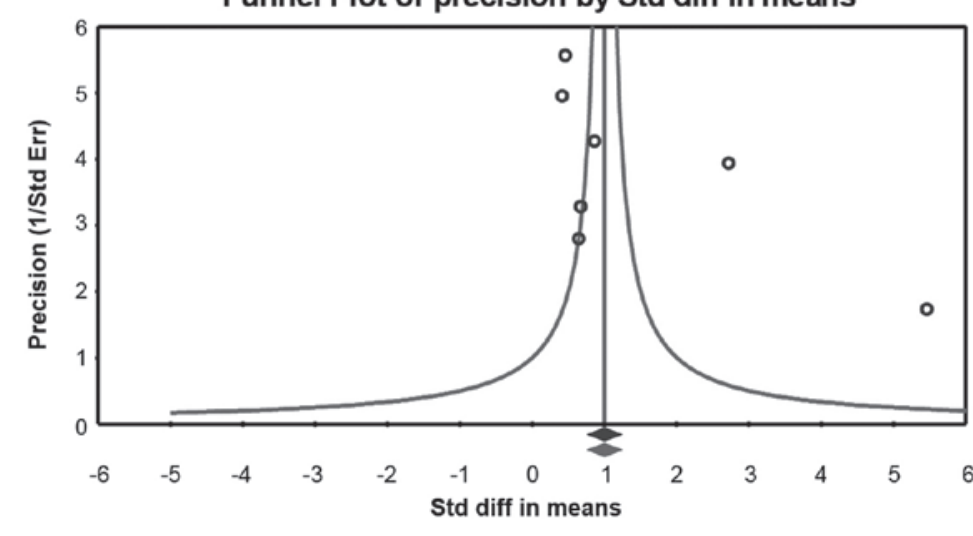

$\begin{array}{lr}\text { Classic fail-safe } \mathbf{N} & \\ \text { Z-value for observed studies } & 12.28619 \\ \text { P-vave for observed studes } & 0.00000 \\ \text { Alpha } & 0.05000 \\ \text { Tails } & 2.00000 \\ \text { Z for alpha } & 1.95996 \\ \text { Number of observed studies } & 7.00000 \\ \text { Number of missing studies that would bring p-value to > alpha } & 269.00000 \\ \text { Egger's regression intercept } & \\ \text { Intercept } & \\ \text { Standard error } & 9.12413 \\ \text { 95\% lower fimit (2-taled) } & 4.70315 \\ \text { 95\% upper limit (2-tailed) } & -2.96570 \\ \text { t-value } & 21.21395 \\ \text { df } & 1.94000 \\ \text { P-value (1-tailed) } & 5.00000 \\ \text { P-value (2-tailed) } & 0.05504 \\ & 0.11000\end{array}$

C

Histological grade: G1/G2 vs. G3

Funnel Plot of precision by Log odds ratio

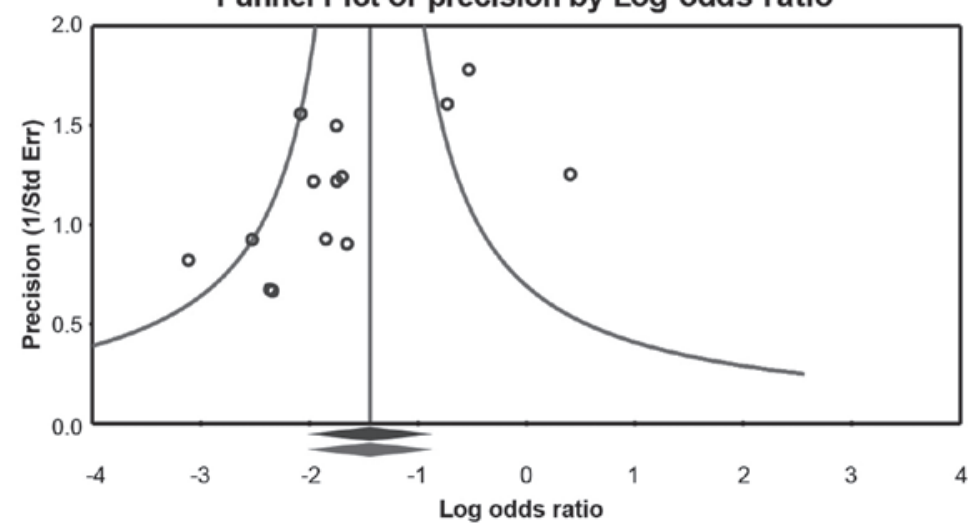

Classic fail-safe $\mathbf{N}$

Z-value for observed studies $\quad-6.94504$

P.value for observed studies $\quad 0.00000$

Apha

Tals

$\begin{array}{lr}Z \text { for alpha } & 1.95096 \\ \text { Number of observed studies } & 15.00000\end{array}$

0.05000

Number of missing studies that would bring p-value to > alpha 174.00000

Egger's regression intercept

Intercept

Standard error $\quad 0.79078$

$-1.82338$

$95 \%$ upper Init (2-tailed)

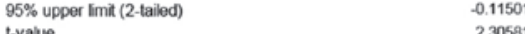

$\begin{array}{lr}\text { t-value } & 2.30581 \\ \text { df } & 1300000\end{array}$

$\begin{array}{lr}\text { df } & 13.00000 \\ \text { P-value (1-taled) } & 0.01912\end{array}$

$\begin{array}{ll}\text { P-value (2-taled) } & 0.03924\end{array}$

Figure 5. Funnel plot of publication biases on (A) the expression rate and (B) protein levels of MMP-9 in bladder cancer patients and healthy control individuals, and (C) the expression rate of MMP-9 in patients with histological grade G1/G2 and G3 tumors. Std diff, standard deviation; Std Err, standard error; df, degrees of freedom; MMP-9, matrix metalloproteinase-9.

The role of MMPs in tumor progression, angiogenesis and in various inflammatory diseases is well documented $(54,58)$. MMP-9 is mainly expressed by macrophages, neutrophils and mast cells (41). The inflammatory response is often associated with advanced neoplasia, which may also induce the overproduction of MMP-9 (59). The present results suggest that the serum MMP-9 level is an important molecular biomarker, which may identify the initiation and predict the progression of bladder cancer. In addition to the elevated MMP-9 levels identified in bladder cancer tissue, the present study observed that the MMP-9 levels were significantly increased in patients with higher grade tumors. Therefore, MMP-9 is associated with the clinicopathological features of bladder cancer. 
The present study also conducted subgroup analysis based on ethnicity. The present results revealed that the rate of MMP-9 protein expression between bladder cancer patients and healthy control individuals was significantly different in African, Asian and Caucasian patients. However, the MMP-9 protein levels in bladder cancer patients and healthy control individuals were significantly different between Asian and Caucasian study subjects, but not between Asian or Caucasian and African study subjects. The expression rate of MMP-9 between G1/G2 and G3 grade tumors was similar, which may be due to the small sample size in the present meta-analysis.

There are limitations in the present meta-analysis that should be acknowledged. First, the sample size was relatively small; therefore the present results lacked sufficient statistical power to fully investigate the association between MMP-9 expression and the pathogenesis of bladder cancer. Second, of the 23 eligible studies, the majority of studies $(n=14)$ were performed using the Chinese population, therefore indicating selection bias. Additional studies using a larger sample size are required to provide a more accurate statistical analysis that is representative of the world population.

In conclusion, the results of the present meta-analysis demonstrated that MMP-9 is associated with the clinicopathological features of bladder cancer, suggesting that MMP-9 may be used in combination with other tumor-specific markers, which may improve the sensitivity of diagnosis and treatment of bladder cancer.

\section{References}

1. Burger M, Catto JW, Dalbagni G, Grossman HB, Herr H, Karakiewicz P, Kassouf W, Kiemeney LA, La Vecchia C, Shariat S and Lotan Y: Epidemiology and risk factors of urothelial bladder cancer. Eur Urol 63: 234-241, 2013.

2. Menashe I, Figueroa JD, Garcia-Closas M, Chatterjee N, Malats N, Picornell A, Maeder D, Yang Q, Prokunina-Olsson L, Wang Z, et al: Large-scale pathway-based analysis of bladder cancer genome-wide association data from five studies of European background. PLoS One 7: e29396, 2012.

3. Kumar B, Koul S, Petersen J, Khandrika L, Hwa JS Meacham RB, Wilson S and Koul HK: p38 mitogen-activated protein kinase-driven MAPKAPK2 regulates invasion of bladder cancer by modulation of MMP-2 and MMP-9 activity. Cancer Res 70: 832-841, 2010.

4. Gui Y, Guo G, Huang Y, et al: Frequent mutations of chromatin remodeling genes in transitional cell carcinoma of the bladder. Nat Genet 43: 875-878, 2011

5. Samplaski MK, Heston W, Elson P, Magi-Galluzzi C and Hansel DE: Folate hydrolase (prostate-specific membrane [corrected] antigen) 1 expression in bladder cancer subtypes and associated tumor neovasculature. Mod Pathol 24: 1521-1529, 2011.

6. Yan Y, Liang H, Li T, Li M, Li R, Qin X and Li S: The MMP-1, MMP-2, and MMP-9 gene polymorphisms and susceptibility to bladder cancer: A meta-analysis. Tumour Biol 35: 3047-3052, 2014.

7. Said N, Frierson HF, Sanchez-Carbayo M, Brekken RA and Theodorescu D: Loss of SPARC in bladder cancer enhances carcinogenesis and progression. J Clin Invest 123: 751-766, 2013.

8. Zhuo W, Zhang L, Cai L, Zhu B and Chen Z: XRCC1 Arg399Gln polymorphism and bladder cancer risk: Updated meta-analyses based on 5767 cases and 6919 controls. Exp Biol Med (Maywood) 238: 66-76, 2013.

9. Offersen BV, Knap MM, Horsman MR, Verheijen J, Hanemaaijer R and Overgaard J: Matrix metalloproteinase-9 measured in urine from bladder cancer patients is an independent prognostic marker of poor survival. Acta Oncol 49: 1283-1287, 2010.

10. Jacobs BL, Lee CT and Montie JE: Bladder cancer in 2010: How far have we come? CA Cancer J Clin 60: 244-272, 2010.
11. Burger M, Oosterlinck W, Konety B, Chang S, Gudjonsson S, Pruthi R, Soloway M, Solsona E, Sved P, Babjuk M, et al; International Consultation on Urologic Disease-European Association of Urology Consultation on Bladder Cancer 2012: ICUD-EAU International Consultation on Bladder Cancer 2012: Non-muscle-invasive urothelial carcinoma of the bladder. Eur Urol 63: 36-44, 2013.

12. Bauvois B: New facets of matrix metalloproteinases MMP-2 and MMP-9 as cell surface transducers: Outside-in signaling and relationship to tumor progression. Biochim Biophys Acta 1825: 29-36, 2012.

13. Zitka O, Kukacka J, Krizkova S, Huska D, Adam V, Masarik M, Prusa R and Kizek R: Matrix metalloproteinases. Curr Med Chem 17: 3751-3768, 2010.

14. Surgucheva I, Chidambaram K, Willoughby DA and Surguchov A: Matrix metalloproteinase 9 expression: New regulatory elements. J Ocul Biol Dis Infor 3: 41-52, 2010.

15. Eissa S, Badr S, Elhamid SA, Helmy AS, Nour M and Esmat M: The value of combined use of survivin mRNA and matrix metalloproteinase 2 and 9 for bladder cancer detection in voided urine. Dis Markers 34: 57-62, 2013

16. Vandooren J, Van den Steen PE and Opdenakker G: Biochemistry and molecular biology of gelatinase B or matrix metalloproteinase-9 (MMP-9): The next decade. Crit Rev Biochem Mol Biol 48: 222-272, 2013.

17. Kessenbrock K, Plaks V and Werb Z: Matrix metalloproteinases: Regulators of the tumor microenvironment. Cell 141: 52-67, 2010.

18. Gunes M, Kemik AS, Pirincci N, Gecit I, Taken K, Yuksel MB Kaba M and Eryilmaz R: Preoperative levels of matrix metalloproteinase-7 and -9 and tissue inhibitor of matrix metalloproteinase-1 relation to pathologic parameters in bladder carcinoma patients. Asian Pac J Cancer Prev 14: 873-876, 2013.

19. Urquidi V, Chang M, Dai Y, Kim J, Wolfson ED, Goodison S and Rosser CJ: IL-8 as a urinary biomarker for the detection of bladder cancer. BMC Urol 12: 12, 2012.

20. Goodison S, Chang M, Dai Y, Urquidi V and Rosser CJ: A multi-analyte assay for the non-invasive detection of bladder cancer. PLoS One 7: e47469, 2012.

21. Chen H, Manning AK and Dupuis J: A method of moments estimator for random effect multivariate meta-analysis. Biometrics 68: 1278-1284, 2012.

22. Higgins JP and Thompson SG: Quantifying heterogeneity in a meta-analysis. Stat Med 21: 1539-1558, 2002.

23. Jackson D, White IR and Riley RD: Quantifying the impact of between-study heterogeneity in multivariate meta-analyses. Stat Med 31: 3805-3820, 2012.

24. Peters JL, Sutton AJ, Jones DR, Abrams KR and Rushton L: Comparison of two methods to detect publication bias in meta-analysis. JAMA 295: 676-680, 2006.

25. Zintzaras E and Ioannidis JP: Heterogeneity testing in meta-analysis of genome searches. Genet Epidemiol 28: 123-137, 2005.

26. Sterne JA and Egger M: Funnel plots for detecting bias in meta-analysis: Guidelines on choice of axis. J Clin Epidemiol 54: 1046-1055, 2001

27. Wikstrom EA, Naik S, Lodha N and Cauraugh JH: Balance capabilities after lateral ankle trauma and intervention: A meta-analysis. Med Sci Sports Exerc 41: 1287-1295, 2009.

28. Egger M, Davey Smith G, Schneider M and Minder C: Bias in meta-analysis detected by a simple, graphical test. BMJ 315: 629-634, 1997.

29. Zhao B, Wang Q, Lei Y, Zhang G, Li R and Song Z: Study on the expression of MMP-9 and CD34 in bladder urothelial carcinoma and their correlation. J Clin Res 31: 1518-1521, 2014 (In Chinese).

30. Bianco FJ Jr, Gervasi DC, Tiguert R, Grignon DJ, Pontes JE, Crissman JD, Fridman R and Wood DP Jr: Matrix metalloproteinase-9 expression in bladder washes from bladder cancer patients predicts pathological stage and grade. Clin Cancer Res 4: 3011-3016, 1998.

31. Eissa S, Ali-Labib R, Swellam M, Bassiony M, Tash F and El-Zayat TM: Noninvasive diagnosis of bladder cancer by detection of matrix metalloproteinases (MMP-2 and MMP-9) and their inhibitor (TIMP-2) in urine. Eur Urol 52: 1388-1396, 2007.

32. Eissa S, Labib RA, Mourad MS, Kamel K and El-Ahmady O: Comparison of telomerase activity and matrix metalloproteinase-9 in voided urine and bladder wash samples as a useful diagnostic tool for bladder cancer. Eur Urol 44: 687-694, 2003.

33. Zhu F, Zhang Y, Yan R, Zhang HQ and Zhang YJ: Correlation of expressions of MMP-2 and MMP-9 in the transitional cell carcinoma of bladder with tremor invasion and metastasis. Zhong Liu Yan Jiu Yu Lin Chuang 21: 680-682, 2009 (In Chinese). 
34. Zhang FM, Gao XM and Li SS, Li SB, Liu Y and Xu H: Expressions of MMP-9 and VEGF in 65 cases with bladder transitional cell carcinoma and their significance. Zhong Liu Xue Za Zhi 15: 1032-1034, 2009 (In Chinese).

35. Guan KP, Ye HY, Yan Z, Wang Y and Hou SK: Serum levels of endostatin and matrix metalloproteinase-9 associated with high stage and grade primary transitional cell carcinoma of the bladder. Urology 61: 719-723, 2003.

36. Zhang JF, Sun LJ, Luo B, Hao J, Song BL and Liu P: Expression of survivin, MMP-9 and PTEN proteins in bladder carcinoma. Xian Dai Yu Fang Yi Xue 37: 4681-4682, 2010 (In Chinese).

37. Guo JH, Wang HR and Wang J, Zhu J and Song HY: Expression of matrix metalloproteinase-9 and its correlation with tumor interstitial microvascular density and tumor metastasis in transitional cell carcinoma of the bladder. Zhong Guo Ai Zheng Za Zhi 14: 116-118, 2004 (In Chinese).

38. Wang JH, Chen ZF, Chen WB and Shi Z: Expression of MMP-9 and TIMP-1 in bladder cancer and its significance. Xian Dai Mi Niao Wai Ke Za Zhi 9: 140-141, 2004 (In Chinese).

39. Chen JS, Yang WM, Xu YM and Wang SL: The expression of MMP-9 and cyclin E in bladder urothelial carcinoma and their clinical significance. Xian Dai Mi Niao Wai Ke Za Zhi 26: 726-731, 2011 (In Chinese).

40. Nutt JE, Durkan GC, Mellon JK and Lunec J: Matrix metalloproteinases (MMPs) in bladder cancer: The induction of MMP9 by epidermal growth factor and its detection in urine. BJU Int 91: 99-104, 2003.

41. Ramón de Fata F, Ferruelo A, Andrés G, Gimbernat H, Sánchez-Chapado $M$ and Angulo JC: The role of matrix metalloproteinase MMP-9 and TIMP-2 tissue inhibitor of metalloproteinases as serum markers of bladder cancer. Actas Urol Esp 37: 480-488, 2013.

42. Zheng XY, Pang X, Wang FJ and Zhu ZQ: Expression of CXCR4 and MMP-9 in bladder transitional cell carcinoma tissue. Xian Dai Sheng Wu Yi 12: 5255-5260, 2012 (In Chinese)

43. Wu Y and Zeng FQ: Expression of MMP-9/TIMP-1 in bladder and the clinical significance transitional cell carcinoma. Xian Dai Mi Niao Wai Ke Za Zhi 20: 577-580, 2005 (In Chinese).

44. Sun YX, Zhang ZC, Sun LQ and Gao HW: Correlation of content and expression of matrix metalloproteinases in transitional cel carcinoma of bladder with tumor invasion and metastasis. Ji Lin Da Xue Xue Bao (Yi Xue Ban) 31: 127-129, 2005 (In Chinese).

45. Tang ZH, Guo SX, Cai QF and Chen TL: Expressions of MMP-9 and TIMP-1 and their relationship with the invasion and metastasis of bladder cancer. Guo Ji Mi Niao Xi Tong Za Zhi 27 : 148-152, 2007 (In Chinese).

46. Zhong A, Yang WM and Ye ZQ: The expression of urinary MMP2 and MMP9 in the bladder transitional cell carcinoma and their correlations to the tumor invasion and metastasis. Chuang Wai Ke Za Zhi 14: 655-657, 2006 (In Chinese).

47. Zhu ZQ, Zheng XY, Zhu QH, Wen JH and Fan CH: Expression and clinical significance of CXCR4 and MMP-9 in bladder cancer. Zhong Guo Xian Dai Yi Xue Za Zhi 19: 337-340,343, 2009 (In Chinese).
48. Lu P, Takai K, Weaver VM and Werb Z: Extracellular matrix degradation and remodeling in development and disease. Cold Spring Harb Perspect Biol 3: a005058, 2011.

49. Jacob-Ferreira AL, Lacchini R, Gerlach RF, Passos CJ, Barbosa F Jr and Tanus-Santos JE: A common matrix metalloproteinase (MMP)-2 polymorphism affects plasma MMP-2 levels in subjects environmentally exposed to mercury. Sci Total Environ 409: 4242-4246, 2011.

50. Castro MM, Rizzi E, Rodrigues GJ, Ceron CS, Bendhack LM, Gerlach RF and Tanus-Santos JE: Antioxidant treatment reduces matrix metalloproteinase-2-induced vascular changes in renovascular hypertension. Free Radic Biol Med 46: 1298-1307, 2009.

51. Ceron CS, Castro MM, Rizzi E, Montenegro MF, Fontana V, Salgado MC, Gerlach RF and Tanus-Santos JE: Spironolactone and hydrochlorothiazide exert antioxidant effects and reduce vascular matrix metalloproteinase- 2 activity and expression in a model of renovascular hypertension. Br J Pharmacol 160: 77-87, 2010.

52. O-Charoenrat $\mathrm{P}$ and Khantapura $\mathrm{P}$ : The role of genetic polymorphisms in the promoters of the matrix metalloproteinase- 2 and tissue inhibitor of metalloproteinase-2 genes in head and neck cancer. Oral Oncol 42: 257-267, 2006.

53. Gialeli C, Theocharis AD and Karamanos NK: Roles of matrix metalloproteinases in cancer progression and their pharmacological targeting. FEBS J 278: 16-27, 2011.

54. Srivastava P, Mandhani A, Kapoor R and Mittal RD: Role of MMP-3 and MMP-9 and their haplotypes in risk of bladder cancer in North Indian cohort. Ann Surg Oncol 17: 3068-3075, 2010.

55. Sand JM, Larsen L, Hogaboam C, Martinez F, Han M, Røssel Larsen M, Nawrocki A, Zheng Q, Karsdal MA and Leeming DJ: MMP mediated degradation of type IV collagen alpha 1 and alpha 3 chains reflects basement membrane remodeling in experimental and clinical fibrosis - validation of two novel biomarker assays. PLoS One 8: e84934, 2013.

56. Reis ST, Leite KR, Piovesan LF, Pontes-Junior J, Viana NI, Abe DK, Crippa A, Moura CM, Adonias SP, Srougi M and Dall'Oglio MF: Increased expression of MMP-9 and IL-8 are correlated with poor prognosis of Bladder Cancer. BMC Urol 12: 18, 2012.

57. Kumar B, Koul S, Petersen J, Khandrika L, Hwa JS, Meacham RB, Wilson S and Koul HK: p38 mitogen-activated protein kinase-driven MAPKAPK2 regulates invasion of bladder cancer by modulation of MMP-2 and MMP-9 activity. Cancer Res 70: 832-841, 2010

58. Stankovic S, Konjevic G, Gopcevic K, Jovic V, Inic M and Jurisic V: Activity of MMP-2 and MMP-9 in sera of breast cancer patients. Pathol Res Pract 206: 241-247, 2010.

59. Zamilpa R, Ramirez TA, Dai Q, Dayah T, Nguyen N, Zhang J, Ahuja SS, D'Armiento, Jin YF and Lindsey ML: MMP-9 overexpression in macrophages regulates the post-myocardial infarction inflammatory response through SCYE1. FASEB J 26 (Suppl): 399.2, 2012. 